
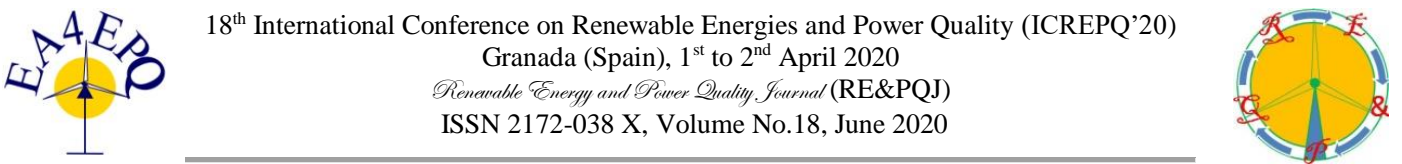

\title{
Effect of building materials on temperature evolution inside the premises in Algeria
}

\author{
F. Hadji ${ }^{1}$, N. Ihaddadene ${ }^{* 1,2}$, R. Ihaddadene ${ }^{1,2}$, M. Choudira ${ }^{1}$, A. Hami ${ }^{1}$ and M. Bekkari ${ }^{3}$ \\ ${ }^{1}$ Department of Mechanical Engineering \\ M'Sila University \\ 28000 M'Sila (Algeria) \\ *Phone/Fax number:+00213 778 417517, e-mail: feres.hadji@univ-msila.dz, MAZ1dz@gmail.com, \\ razika.ihaddadene@univ-msila.dz \\ ${ }^{2}$ Renewable Energy and Sustainable Development Laboratory, Constantine University \\ 25000 Constantine (Algeria) \\ ${ }^{3}$ GTFT maintenance department (Algeria)
}

\begin{abstract}
The building sector is partially in charge of the exhaustion of conventional energy sources, global warming, and environmental pollution. This experimental investigation is devoted to the study of the thermal behaviour of three different building materials used in Algeria, namely sheep wool, traditional brick, and ordinary brick, under real conditions. Three identical chambers were built made of the above-cited materials. Three temperature sensors were placed in the center of the three chambers, which were aligned and separated by approximately $10 \mathrm{~cm}$. The digital acquisition system based on the Arduino board allows us to measure and record temperatures in the middle of the three well-closed rooms for one day (day and night) by oneminute steps. The temperature of the ambient air (outdoor temperature), used as a reference, was taken too. It is found that the thermo-physical properties (thermal diffusivity) of the building materials, in addition to the thickness of the building envelope (walls and roof), play an important role in the heat exchange between the indoor and outdoor. This study aims to encourage the reuse of the traditional bricks seen their advantages in energy saving and environmental preservation.
\end{abstract}

Key words. Building materials, temperature, traditional brick, arduino board, ordinary brick.

\section{Introduction}

A building is defined in common sense as a construction intended to be used as a shelter or habitat to protect people and property from outside weather conditions. The building is known for its high energy consumption (first disadvantage). It is considered as one of the largest energyconsuming sectors in the world in addition to industry and transportation. [1] Indeed, it is reported that $25 \%$ to $40 \%$ of the primary energy is consumed by the building sector in most countries. [2]-[5]. This energy is intended to guarantee, in particular, a comfortable indoor environment (cooling and heating) [6], which improves the efficiency of the work and ensure the health of the occupants. [1]
In Algeria, the building sector consumes $34 \%$ of the national final energy. Moreover, the annual average energy consumption of a dwelling in this country between 2000 and 2012 is about 54.55 GJ, as pointed out by the National Agency for the Promotion and Rationalization of the energy use (APRUE) [7]. It is the first largest electricity sector consumer nationally. [7]

On the other hand, the building sector presents a negative impact on the environment (second disadvantage). Indeed, since it is one of the greatest consumers of conventional energies (fossil fuels), it releases large amounts of greenhouse gases into the atmosphere, especially $\mathrm{CO}_{2}$ [6],[8]-[11], responsible for climatic warming. Moreover, the amount of $\mathrm{CO}_{2}$ released by the building sector was 6.8 billion tons in 2004 and is forecast to reach 15.6 billion tons in the year 2030. [2]

Thus, the building sector is partially in charge of the exhaustion of conventional energy sources, global warming, and environmental pollution. Therefore, it is necessary to solve these problems by mitigating building energy consumption. [1],[2] Saving energy in the building sector is not difficult to make. It is not like in the industrial and transportation sectors. [12]

As known, the building loses and gains heat in the winter and summer seasons, respectively, through any part of the building envelope (walls, windows, floor, roof, etc.), due to the temperature difference between the inside and outside of the building. Most heat exchanges (heat loss or gain) occur through the exterior walls [13],[14], whose thermal performances depend on their building materials.

Earthen (adobe, cob, rammed earth, and wattle and daub) home constructions are known as passive solar buildings (naturally air-conditioned). [15] Earthen building 
materials have low thermal conductivity [16],[17]. Hence, they could be used for building thermal insulation, reducing, thus, its energy consumption. Earthen building materials have the advantages to be easily accessible, inexpensive, and environmentally friendly.

This study is a continuation of our works on natural building materials. After showing their ability to be used as insulation for thermal collectors in our first investigation [18] and then determining experimentally the thermal conductivity of different natural building materials [19] (second work). This third investigation (an experimental work) compares the evolution of the temperature inside the premises of different building materials used in Algeria (i.e., the thermal behaviour of different building materials under real conditions).

\section{Materials and Methods}

\section{A. Building materials}

Three different building materials used in Algeria were employed in this investigation, namely sheep wool, traditional brick, and ordinary brick.

The tent is the habitat used by the nomads of southern Algeria until now. It is made of sheep wool (one of the materials chosen for this study). The traditional brick or adobe brick is made by mixing straw and earth in proportions well-known, according to the know-how of the inhabitants where this study took place (M'Sila region). A detailed description of how to obtain these traditional bricks is given in our previous paper. [19] Unfortunately, traditional bricks are no longer used in Algeria today despite their advantages. Ordinary brick is a hollow terracotta brick, dried using very high-temperature furnaces. It is the material used nowadays in house construction in Algeria.

\section{B. Rooms}

Three identical chambers of $20 \times 20 \times 20 \mathrm{~cm}^{3}$ were built made of sheep wool, adobe brick, and ordinary brick to study the evolution of the temperature inside them (indoor temperature), as illustrated in Figure 1.

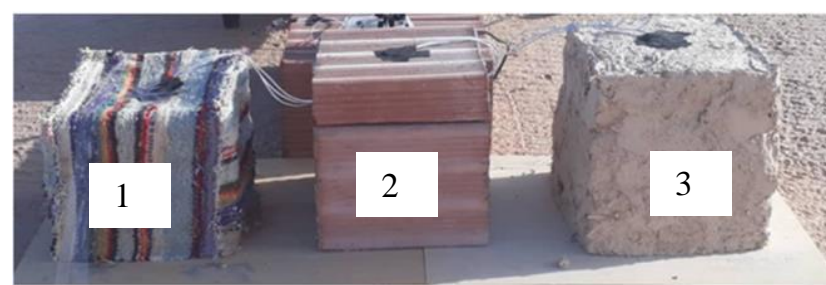

Fig. 1. Three different chambers made of sheep wool (1) (tent), ordinary brick (2), and adobe brick (3).

For the tent, the sheep wool fabric wraps a wooden frame that has the same dimensions as the two other rooms. It is worthy to note that the interior volume of the three chambers is identical. The walls of the brick rooms (adobe and ordinary bricks) have a similar thickness $(5 \mathrm{~cm})$. For this reason, these two chambers have the same exterior volume. Conversely, the tent has the lowest external volume, seen the thickness of the wool fabric, which is 0.5 $\mathrm{cm}$ (see again Figure 1). The walls of the ordinary brick room are well cemented (i.e., sealed with cement), as in usual dwellings.

Table I shows the thermal conductivity of the studied materials taken from literature studies.

Table I. Range of the thermal conductivity of the materials used

\begin{tabular}{|c|c|}
\hline Material & $\begin{array}{c}\text { Thermal conductivity } \\
(\mathrm{W} / \mathrm{mK})\end{array}$ \\
\hline Sheep wool & $0.04[20]$ \\
\hline Ordinary brick & $0.61-0.74[21]$ \\
\hline Adobe brick & $0.2-0.93$ \\
\hline
\end{tabular}

\section{Digital acquisition system}

The digital acquisition system has been used to record the evolution of the temperature inside the chambers made of different materials for 24 hours with a one-minute time interval. It is mainly composed of the Arduino UNO board (Figure 2) and four LM35 temperature sensors (Figure 3), in addition to connector cables (Figure 4).

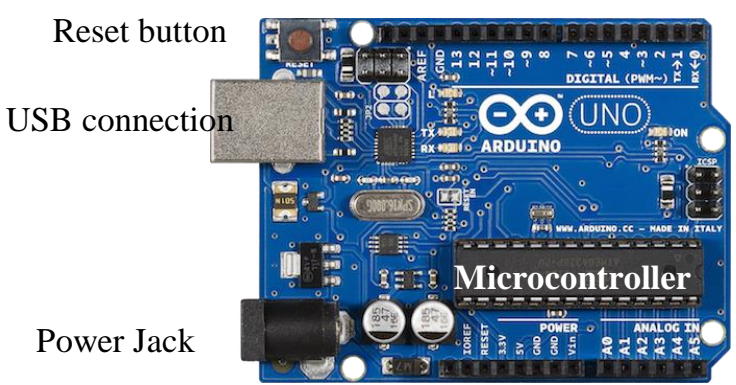

Fig. 2. Arduino Uno board.

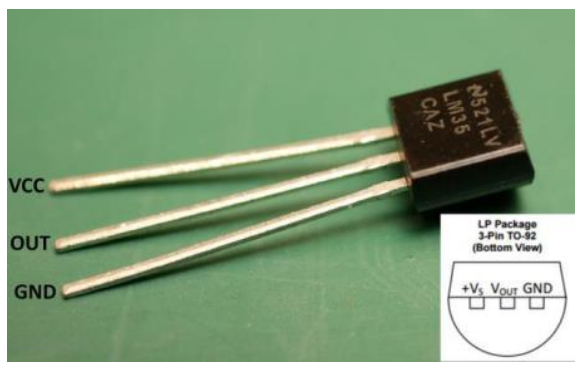

Fig. 3. LM35 temperature sensor.

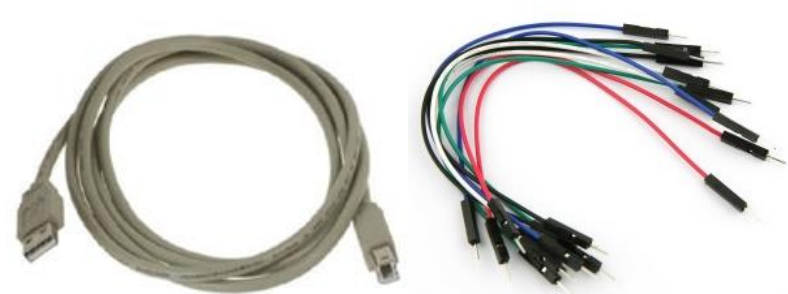

Fig. 4. Wirings of the electronic assembly used.

The Arduino Uno board is the most popular and easiest electronic board to use. It is the one chosen for our digital acquisition system (Figure 2). The Arduino Uno board is a card equipped with a microcontroller of 8-bit AVR family: the ATMega 328. It is composed of 20 digital input/output pins (Six (6) pins can be used as analog outputs and six (6) others as PWM inputs), a USB connection, a $16 \mathrm{MHz}$ resonator, a power jack, an in- 
circuit system programming (ICSP) header, and a reset button (see again Figure 2).

The LM35 temperature sensor is an analog temperature sensor manufactured by Texas Instruments. It is extremely popular since it is accurate, inexpensive, easy to use, and reliable. In addition, LM35 is capable of measuring temperatures from $-55^{\circ} \mathrm{C}$ to $+150{ }^{\circ} \mathrm{C}$.

The VCC pin must be connected to the $5 \mathrm{~V}$ pin on the Arduino. The GND of the sensor must be connected to the GND on the Arduino. Finally, the OUT pin (the one that sends the information) must be connected to one of the analog pins, for example, pin A0 (see Figure 2 and Figure 3).

Furthermore, the Arduino board is equipped with the necessary program for the operation of the LM35 sensor.

The recorded temperature measurements were displayed on a PC computer connected to the Arduino board via USB cable (Figure 5).

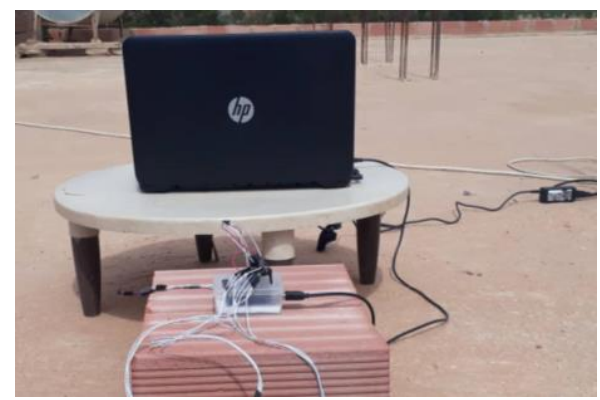

Fig. 5. Connection of the acquisition system to the PC computer (display and recording of the measured values).

\section{Experimental procedure}

The experiment studying the thermal behaviour of the three building materials was carried out in open air under outdoor conditions for one day (24 hours).

Three temperature sensors were placed in the middle of the three chambers, which were aligned and separated by approximately $10 \mathrm{~cm}$ (see again Figure 1).

The digital acquisition system based on the Arduino board allows us to measure and record temperatures in the center of the three well-closed rooms for one day (day and night) by one-minute steps. The temperature of the ambient air (outdoor temperature), used as a reference, was taken too. This experiment was performed one day of April month.

\section{Results and discussion}

Figure 6 shows the evolution of the temperature in the center of three identical rooms made of different materials, namely, sheep wool (tent), ordinary brick, and traditional brick (earth + straw), in comparison with the ambient temperature during a sunny day of April month (24 hours). It can be seen that the temperatures in the middle of the three chambers (indoor temperatures) follow the same pace as that of the outdoor. They admit two extremes; a minimum recorded in the morning and a maximum in the afternoon.

As known, the temperature of the air (ambient temperature) depends on the solar energy received by the earth's surface.

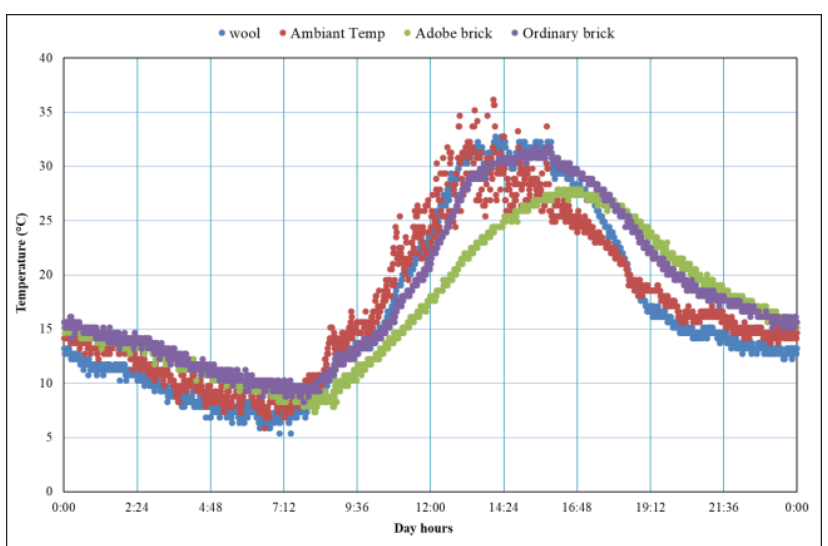

Fig. 6. Indoor temperature evolution of a tent, an ordinary brick room, and a traditional brick room for a day ( 24 hours).

Indeed, during the day, the earth receives solar radiation that warms the ambient air. As a consequence, its temperature increases, as seen in our case (Figure 6), from 6:35 AM to 2:03 PM.

Moreover, the solar radiation intercepted by the earth peaks at solar noon, where the sun is high in the sky. The ambient air temperature follows the same trend and reaches its maximum after solar noon due to air heat capacity.

The sun continues its trajectory towards the west, where it sets. Its intensity decreases during this path until reaching $0 \mathrm{~W} / \mathrm{m}^{2}$ at sunset. Therefore, the temperature of the air decreases as well, as illustrated in Figure 6.

During the night (from sunset to sunrise), the earth cools, due to heat exchange with the universe, and the temperature of the air continues to drop until sunrise, where it begins to increase again. This air temperature evolution is repeated every day.

The indoor temperature is influenced by the building material of the chambers as it differs from room to room (see again Figure 6). Indeed, during the day, the maximum outdoor ambient temperature is reduced by $3.42{ }^{\circ} \mathrm{C}$ inside the tent, by $8.31{ }^{\circ} \mathrm{C}$ inside the traditional brick chamber, and by $4.4{ }^{\circ} \mathrm{C}$ inside the ordinary brick chamber.

In addition, the maximum temperatures inside the three chambers do not occur at the same time as the outdoor temperature (time lag). Effectively, the graphs showing the evolution of the indoor temperature of the three chambers are shifted towards the right relative to the graph of the outdoor temperature as illustrated in Figure 6.

Furthermore, the time lag is estimated at $4 \mathrm{~min}, 1 \mathrm{~h} 22$ $\mathrm{min}$, and $2 \mathrm{~h} 6 \mathrm{~min}$ for the tent, the ordinary brick room, and the traditional brick room, respectively. The maximum temperature inside the three rooms occurs after that of the outside because of the heat capacity of the building materials used.

Thus, the houses are shelters against the external conditions since the indoor temperatures during the day are reduced compared to that of the external environment (thermal resistance to heat gains).

During the day, the traditional brick chamber presents the highest time lag and the lowest temperature peak. In contrast, the tent presents the lowest time lag and the highest temperature peak (see again Figure 6). In other 
words, the outside environment heat passes easily through the sheep wool fabric, and hardly through the traditional brick. This is due, as mentioned above, to the thermophysical properties (thermal conductivity, heat capacity, and density) of the materials used, in addition to the thickness of the envelope of the chambers (walls and roof). Despite the very low thermal conductivity of the sheep wool of the order of $0.04 \mathrm{~W} / \mathrm{m} . \mathrm{K}$ [20] (classified as insulation), its low thickness $(0.5 \mathrm{~cm})$ promotes the thermal exchange between the outside environment and the inside of the tent, hence the small difference recorded between the outdoor and indoor temperatures (see again Figure 6 and Figure 7). This experimental result confirms the numerical outcome found by Asan. [22]

In reality, the base (ground) of the tents used in the Saharan climates undergoes humidification that cools the indoor environment and gives it a thermal comfort during the summer days. In addition to the shape of the tent, which is not a closed cube (see Figure 8), this form enhances the thermal comfort inside the tent.

Moreover, this investigation concerns the effect of building materials, that is why we kept the same shape and dimensions of the room, and we just varied their building material.

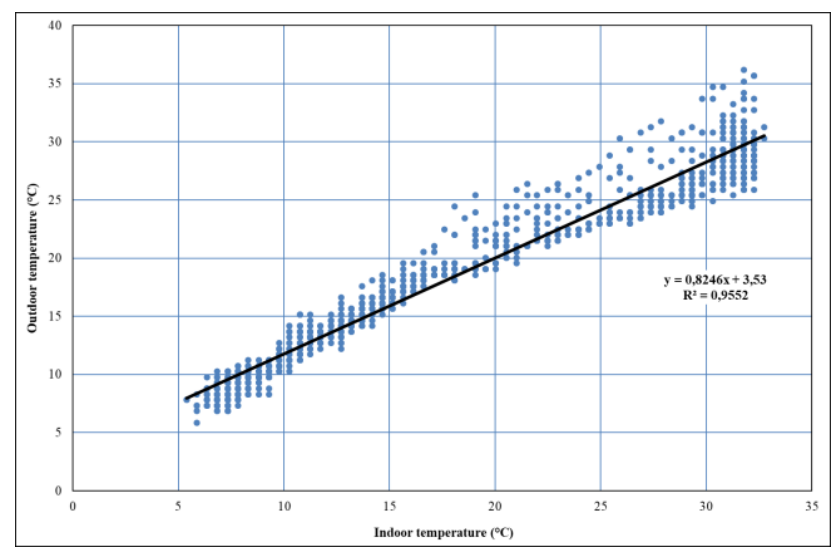

Fig. 7. Outdoor temperature vs. Tent indoor temperature for a day (24 hours).

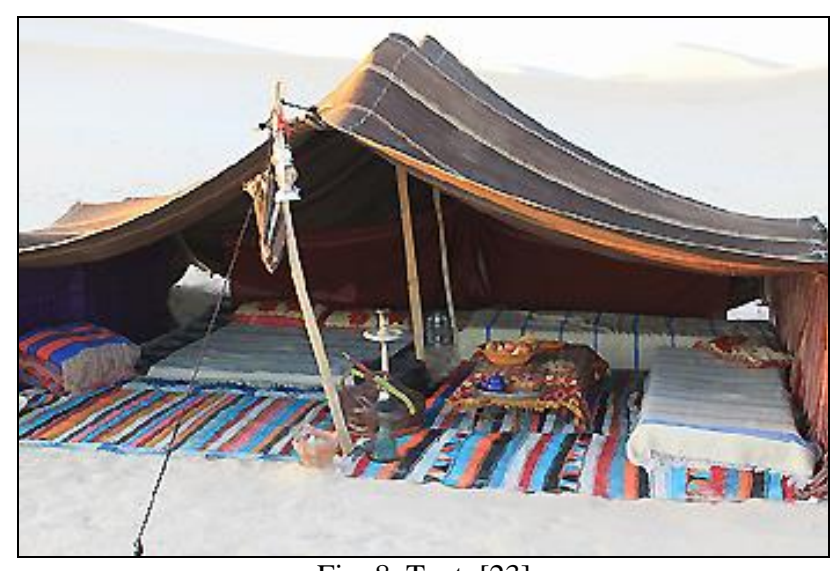

Fig. 8. Tent. [23]

The two remaining chambers have the same thickness but behave differently (see Figure 6 and Figure 9) because of the different thermal diffusivity of their building material. The thermal diffusivity is a material related property. It characterizes unsteady heat conduction and describes the rate of temperature spread through a material. The thermal diffusivity $\alpha$ is given by the following equation:

$$
\alpha=\lambda / \rho c
$$

Where $\lambda$, is the thermal conductivity of the material; $\rho$, the material density; and c, the specific heat capacity of the material.

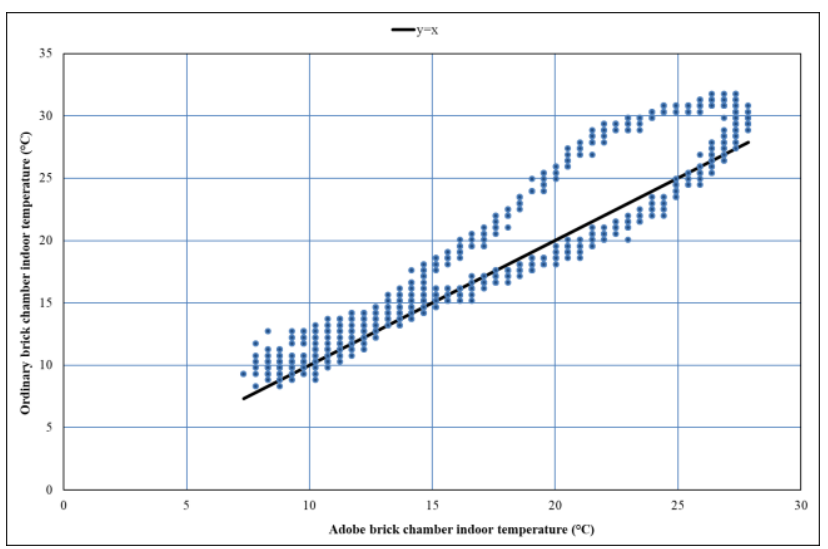

Fig. 9. Comparison between the indoor temperature of the ordinary brick chamber and that of the Adobe brick chamber for one day (24 hours).

Thus, from this experiment, one can say that the thermal diffusivity of the ordinary brick is greater than that of the adobe brick. Indeed, the temperature inside the adobe brick chamber does not exceed $30{ }^{\circ} \mathrm{C}$, while that of the ordinary brick chamber surpasses this value, as seen in Figure 9. This explains why traditional brick houses are cold in summer days without air conditioners.

Moreover, it is found that the thermal diffusivity of the tested materials is inversely proportional to the time lag. Indeed, the tent with the highest thermal diffusivity presents the lowest time lag, and the traditional brick with the lowest diffusivity shows the highest time lag. Again, this experimental result is in agreement with the numerical outcome of Asan. [22]

During the night, the minimum outdoor ambient temperature is reduced by $0.49{ }^{\circ} \mathrm{C}$ inside the tent, increased by $1.46{ }^{\circ} \mathrm{C}$ inside the traditional brick chamber and by $2.44{ }^{\circ} \mathrm{C}$ inside the ordinary brick chamber (see again Figure 6). Furthermore, the time lag is estimated at $29 \mathrm{~min}, 1 \mathrm{~h} 17 \mathrm{~min}$, and $1 \mathrm{~h} 38 \mathrm{~min}$ for the tent, the ordinary brick room, and the traditional brick room, respectively. Again, the minimum temperature inside the three rooms occurs after that of the outside because of the heat capacity of the building materials used (storage energy).

During the night, the tent presents the lowest time lag and the lowest minimum temperature (see again Figure 6). This is due to its highest thermal diffusivity (low thermal conductivity and low thermal capacitance). In other words, the inside heat flows easily through the sheep wool fabric of the tent to the outside environment. Thus, the tent indoor temperature can drop below that of the outside. During the night, the tent is the cold chamber. In contrast, traditional and normal brick rooms are slightly warmer than the outdoor environment.

The difference in indoor temperature between the adobe brick chamber and the ordinary brick chamber is not important (see Figure 9). The same result was found for 
the time lag (see Figure 6). Therefore, both rooms have almost the same behavior at night.

In reality, the adobe chamber needs heating in the winter period, which corresponds in our experience to the night, but once heated, it does not allow the heat to diffuse through its envelope (minimum heat loss). However, the brick chamber presents a lot of heat losses. Hence, it necessitates heat insulation (money spent).

It has been shown quantitatively that traditional brick house has the advantage of being cold during the day and warm at night. The adobe brick stores heat during the day and releases it during the night. It is better placed than ordinary brick.

\section{Conclusion}

This experimental investigation is devoted to the study of the thermal behaviour of three different building materials used in Algeria, namely sheep wool, traditional brick, and ordinary brick, under real conditions.

It is found that the thermo-physical properties (thermal diffusivity) of the building materials, in addition to the thickness of the building envelope (walls and roof), play an important role in the heat exchange between the indoor and outdoor.

It has been shown quantitatively that traditional brick house has the advantage of being cold during the day (summer) and warm at night (winter). The adobe brick stores heat during the day and releases it during the night when the outdoor temperature drops. It is better placed than ordinary brick.

This study aims to encourage the reuse of the traditional brick seen their advantages in energy saving and environmental preservation.

\section{References}

[1] Y. Huang, J. L. Niu, "Optimal building envelope design based on simulated performance : History, current status and new potentials", Energy and Buildings (2016). Vol. 117, pp. 387-398.

[2] H. Huoa, C. Jinga, K. Lib, H. Huoc, "Synergic relationships between thermophysical properties of wall materials in energy-saving building design". International Journal of Heat and Mass Transfer (2015). Vol. 90, pp. 246-253.

[3] European Commission, Energy, transport and environment Indicators, Eurostat (2012).

[4] L. Perez-Lombard, J. Ortiz, C. Pout, "A review on buildings energy consumption information", Energy Build. (2008). Vol. 40, pp, 394-398.

[5] F. Zhang, P. Cooke, Green Building and Energy Efficiency, Center for Advanced Studies, Cardiff University, United Kingdom.

[6] L. Adityaa, T.M.I. Mahliaa, B. Rismanchic, H.M. Ng, M.H. Hasane, H.S.C. Metselaare, O. Murazaf, H.B. Aditiya, "A review on insulation materials for energy conservation in buildings”. Renewable and Sustainable Energy Reviews.
(2017). Vol. 73, pp, 1352-1365.

[7] Review of the National Agency for the Promotion and Rationalization of the energy use, Final Energy Consumption of Algeria, Key figures Year 2012, APRUE (2014). (In French)

[8] K. Gunnell, D.P. Chrisna, J. Gibberd, Green Building In South Africa: Emerging Trends, Department of Environmental Affairs and Tourism, the Republic of South Africa (2009).

[9] E. Opaluwa, P. Obi, O.C. Osasona, Sustainability in traditional African architecture: a springboard for sustainable urban cities, Sustainable Futures. South Kampala, Architecture and Urbanism in the Global South, Uganda (2012).

[10] T.Z. Hong, "A close look at the china design standard for energy efficiency of public buildings", Energy Build (2009). Vol. 41, pp. 426-435.

[11] UNEP. Buildings and Climate Change: Status, Challenges and Opportunities. United Nations Environment Programme, New York, USA (2007), pp. 87.

[12] Y. Jiang, "Current building energy consumption in China and effective energy efficiency measures", J. HVAC (2005). Vol. 35, pp. 30-40.

[13] J. Donnelly, Energy Efficiency in Traditional Buildings, Government of Ireland, Ireland.

[14] A.P. Olukoya Obafemia, S. Kurtb, "Environmental impacts of adobe as a building material: The north cyprus traditional building case, Case Studies in Construction" Materials (2016). Vol. 4, pp. 32-41.

[15] H. Asan, Y.S. Sancaktar, "Effects of Wall's thermophysical properties on time lag and decrement factor", Energy and Buildings (1998). Vol. 28, pp. 159166.

[16] H. Niroumanda, M.F.M. Zainb, M. Jamil, "Various Types of Earth Buildings", 2nd Cyprus International Conference on Educational Research, (CY-ICER 2013), Procedia Social and Behavioral Sciences (Oct.2013). Vol. 89, pp. 226-230.

[17] Binici, H., et al., "Thermal isolation and mechanical properties of fibre reinforced mud bricks as wall materials",

Constr. Build. Mater (2007). Vol. 21 (4), pp. 901-906.

[18] N. Ihaddadene, R. Ihaddadene, A. Betka, "Experimental Investigation of Using a Novel Insulation Material on the Functioning of a Solar Thermal Collector", J. Sol. Energy Eng. (2018). Vol. 140(6), pp. 061001-1(5)

[19] N. Ihaddadene, R. Ihaddadene, A. Betka et al. "Study of the thermal conductivity of clay-based building materials", IAPE'19 (2019), Oxford, United Kingdom.

[20] M. Rossi, V. M. Rocco, "External walls design: The role of periodic thermal transmittance and internal areal heat capacity”, Energy and Buildings (2012). Vol. 68, pp. 732740.

[21] J.Chávez-Galán, R. Almanza, N. R. Cuevas,“Convective heat transfer coefficients: experimental estimation and its impact on thermal building design for walls made of different Mexican building materials", Concreto y Cemento. Investigación y Desarrollo (2014), Vol. 5(2), pp. 26-38.

[22] H. Asan, "Numerical computation of time lags and decrement factors for different building materials", Building and Environment (2006). Vol. 41, pp. 615-620.

[23] http://www.sabria.org/sahara-tunisie-nuit-dans-le-

desert.php 